\title{
Childhood Embryonal Carcinoma
}

National Cancer Institute

\section{Source}

National Cancer Institute. Childhood Embryonal Carcinoma. NCI Thesaurus. Code C123847.

An embryonal carcinoma occurring in children. 